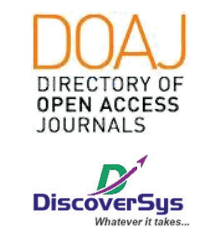

Published by DiscoverSys

\section{Transient Elastography sebagai Alat Skrining Kecurigaan Hipertensi Portal pada Penderita Sirosis Hepatis}

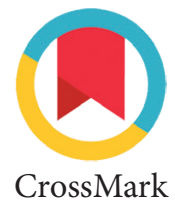

\author{
I Made Wisnu Wardhana, ${ }^{1 *}$ Gde Somayana, ${ }^{2}$ I Ketut Mariadi, ${ }^{2}$ \\ I Dewa Nyoman Wibawa ${ }^{2}$
}

\title{
ABSTRACT
}

Background: Portal hypertension was causes by extensive fibrosis on liver cirrhosis. The diagnosis of portal hypertension can only be identified by invasive procedure. Transient elastography (TE) is a noninvasive examination to determine the level of liver fibrosis by liver stiffness (LS).

Objective: Transient elastography is expected to predict the possibility of portal hypertension in liver cirrhosis.

Methods: The study used a cross-sectional design, where data were analyzed using a receiver operating curve $(\mathrm{ROC})$ to determine the area under the curve (AUC). Data was collected from 2015 to 2018 using consecutive sampling. Analysis were done using SPSS and Medcalc to determine the cut-off point that has the best sensitivity, specificity, positive likelihood ratio (+ LR) and negative likelihood ratio (-LR).
Results: In this study we found 69 patients with hepatic cirrhosis which consisted of 57 men (82.6\%) and 12 women (17.4\%) with a mean age of 48.57 . From 69 patients with cirrhosis, portal hypertension manifestations were found by endoscopy in 45 patients $(65.2 \%)$, while $24(34.8 \%)$ were absent. TE was examined to determine $L S$, where the lowest value was $11.0 \mathrm{kPa}$, the highest value was $75.0 \mathrm{kPa}$, with mean value of $29.89 \mathrm{kPa}$. AUC results for $\mathrm{LS}$ were 0.763 (95\% Cl 0.645 $0.857, \mathrm{p}<0.001)$. The best cut-off point for $\mathrm{LS}$ is above $17.5 \mathrm{kPa}$ with a sensitivity of $82.22 \%$ (95\% Cl 67.9-92.0\%), specificity $62.50 \%$ (95\% Cl 40.6-81.2\%), + LR 2.19 (95\% Cl 1.3-3.7), and - LR 0.28 (95\% Cl 0.1-0.6). Conclusion: Transient elastography with liver stiffness above $17.5 \mathrm{kPa}$ can be used as a screening tool to predict manifestations of portal hypertension in patients with liver cirrhosis.

Keywords: Transient elastography, portal hypertension, liver cirrhosis Cite This Article: Wardhana, I.M.W., Somayana, G., Mariadi, I.K., Wibawa, I.D.N. 2020. Transient Elastography sebagai Alat Skrining Kecurigaan Hipertensi Portal pada Penderita Sirosis Hepatis. Intisari Sains Medis 11(2): 493-496. D0I: 10.15562/ism.v11i2.620

\section{ABSTRAK}

1Program Studi Pendidikan Dokter Spesialis Penyakit Dalam, Fakultas Kedokteran Universitas Udayana / RSUP Sanglah, Denpasar, Bali, Indonesia.

2Departemen / KSM Penyakit Dalam, Fakultas Kedokteran Universitas Udayana / RSUP Sanglah, Denpasar, Bali, Indonesia.

*Korespondensi:

I Made Wisnu Wardhana, Program Studi Pendidikan Dokter Spesialis Penyakit Dalam, Fakultas Kedokteran Universitas Udayana / RSUP Sanglah, Denpasar, Bali, Indonesia. megaloblastik@yahoo.com

Diterima: 16-09-2019

Disetujui: 01-05-2020

Diterbitkan: 01-08-2020
Latar belakang: Hipertensi portal adalah dampak fibrosis ekstensif pada sirosis hepatis. Dimana diagnosis hipertensi portal hanya dapat ditegakkan melalui prosedur invasif. Transient elastography (TE) merupakan pemeriksaan non invasif untuk mengetahui tingkat fibrosis hati dengan hasil berupa liver stiffness (LS).

Tujuan: TE diharapkan dapat digunakan sebagai alat screening bagi penderita sirosis hepatis yang memerlukan tindakan endoskopi.

Metode: Penelitian menggunakan desain potong lintang, dimana data dianalisis dengan menggunakan receiver operating curve (ROC) untuk menentukan area under curve (AUC). Data dikumpulkan dari tahun 2015 hingga 2018 secara konsekutif. Analisis menggunakan SPSS dan Medcalc untuk menentukan titik potong yang memiliki sensitivitas, spesifisitas, positive likelihood ratio (+LR) dan negative likelihood ratio (-LR).

Hasil: Pada penelitian ini didapatkan 69 penderita sirosis hepatis yang terdiri dari 57 orang laki-laki $(82,6 \%)$ dan 12 orang perempuan
$(17,4 \%)$ dengan rata-rata usia 48,57 tahun. Dari 69 penderita sirosis hepatis dilakukan dievaluasi dengan menggunakan endoskopi dimana didapatkan 45 orang $(65,2 \%)$ mengalami manifestasi hipertensi portal, sedangkan 24 orang $(34,8 \%)$ lainnya tidak. Kemudian dilakukan pemeriksaan TE untuk mengetahui LS, dimana didapatkan nilai terendah adalah $11,0 \mathrm{kPa}$, nilai tertinggi $75,0 \mathrm{kPa}$, dengan rata-rata 29,89 kPa. Analisis kurva ROC terhadap LS yang diperoleh dari TE, diperoleh hasil AUC 0,763 (95\% Cl 0,6450.857, $\mathrm{p}<0,001)$. Titik potong untuk $\mathrm{LS}$ adalah $>17,5 \mathrm{kPa}$ dengan sensitivitas 82,22\% (95\% Cl 67,9-92,0\%), spesifisitas 62,50\% (95\% Cl 40,6-81,2\%), +LR 2,19 (95\% Cl 1,3-3,7), dan -LR 0,28 (95\% Cl $0,1-0,6)$.

Simpulan: TE dengan $\mathrm{LS}>17,5 \mathrm{kPa}$ dapat digunakan sebagai alat screening untuk memprediksi adanya manifestasi hipertensi portal dengan interpretasi sedang. 


\section{LATAR BELAKANG}

Sekitar 50\% penderita sirosis hepatis mengalami hipertensi portal. ${ }^{1,2}$ Hipertensi portal pada penderita sirosis terjadi akibat banyaknya aliran darah ke sirkulasi portal disertai peningkatan resistensi aliran darah. ${ }^{3}$ Manifestasi hipertensi portal pada penderita sirosis antara lain varises gastroesofagus, dan gastropati hipertensi portal. Kedua hal ini terjadi akibat terbentuknya aliran darah kolateral agar darah dapat kembali sirkulasi sistemik tanpa melewati hati. ${ }^{4}$

Varises gastroesofagus dan gastropati hipertensi portal dapat menyebabkan perdarahan saluran cerna bagian atas yang akan meningkatkan angka mortalitas pada penderita sirosis hepatis. Pencegahan primer merupakan strategi utama penatalaksanaan varises gastroesofagus dan gastropati hipertensi portal. Oleh karena itu identifikasi secara diniadanya varises gastroesofagus dan gastropati hipertensi portal sebelum terjadinya perdarahan merupakan hal yang sangat penting untuk penderita sirosis hepatis. ${ }^{5}$

Hipertensi portal diketahui dengan perhitungan tekanan portal melalui pengukuran langsung kateterisasi vena portal atau vena hepatika. Namun pemeriksaan ini merupakan tindakan invasif yang menyebabkan aplikasinya secara klinis sukar dilakukan. ${ }^{6}$ Endoskopi merupakan salah satu pemeriksaan tidak langsung untuk mengetahui adanya hipertensi portal dengan melihat manifestasinya yaitu varises gastroesofagus dan gastropati hipertensi portal. Endoskopi adalah prosedur invasif yang membutuhkan tenaga khusus, biaya yang relatif tinggi, serta meskipun rendah terdapat risiko komplikasi paska tindakan. ${ }^{5}$ Transient elastography (TE) adalah salah satu metode liver stiffness measurement yang diharapkan dapat menjadi alat skrining untuk mengetahui adanya kecurigaan manifestasi hipertensi portal sehingga penggunaan endoskopi dapat dibatasi dan pencegahan primer dapat dilakukan lebih dini.

\section{METODE}

Desain penelitian ini adalah studi potong lintang yang dilakukan di Rumah Sakit Umum Pusat Sanglah Denpasar sejak September 2015 hingga September 2018 yang telah disetujui komite etik lokal departemen penyakit dalam FK Universitas Udayana, Bali. Data diambil secara konsekutif. Kriteria inklusi untuk penelitian ini antara lain penderita sirosis hepatis yang dicurigai mengalami hipertensi portal, berusia diatas 18 tahun, dan menjalani pemeriksaan TE dan endoskopi dengan jarak waktu antara kurang dari 1 bulan. Kriteria eksklusi pada studi ini adalah penderita sirosis hepatis dengan asites, kolestasis, obesitas, inflamasi akut, dan gagal jantung kanan. Perhitungan jumlah sampel untuk penelitian ini menggunakan hipotesis satu arah dengan $\alpha=0,05, \beta=0,10$ dan AUC dari penelitian sebelumnya 0,8 , sehingga didapatkan jumlah sampel minimal yang dibutuhkan $61 .{ }^{7}$

Pada penelitian ini pemeriksaan transient elastography untuk mengetahui liver stiffness (LS) yang di ukur dengan menggunakan FibroScan ${ }^{\circledR}$ $\left(\right.$ Echosens $\left.^{\mathrm{m}}\right)$ dalam satuan $\mathrm{kPa}$ dan adanya manifestasi hipertensi portal yaitu varises gastroesofagus dan gastropati hipertensi portal diketahui dengan menggunakan endoskopi (Olympus GIF-p20) yang dilakukan oleh tiga operator yang berbeda.

Data yang dikumpulkan dianalisis dengan menggunakan program IBM SPSS versi 22.0 dan MedCalc. SPSS digunakan untuk uji receiver operating charateristic (ROC) sehingga nilai $\mathrm{p}$ dan area under curve (AUC) dapat diketahui. Sedangkan MedCalc digunakan untuk mengetahui nilai titik potong optimal, sensitivitas, spesifisitas, positive likelyhood ratio (+LR) dan negative likelyhood ratio (-LR).

\section{HASIL}

Pada penelitian ini didapatkan 69 subjek memenuhi kriteria inklusi dan eksklusi. Usia subjek penelitian berkisar antara usia 27 hingga 75 tahun dengan rata-rata usia 48,57 $\pm 10,29$ tahun. Jumlah subjek laki-laki 57 orang dan perempuan 12 orang. Penyebab sirosis hepatis pada subjek penelitian antara lain hepatitis B kronik, hepatitis C kronik, penyakit hati kolestasis, dan penyebab yang belum teridentifikasi. Jumlah subjek yang tidak mengalami

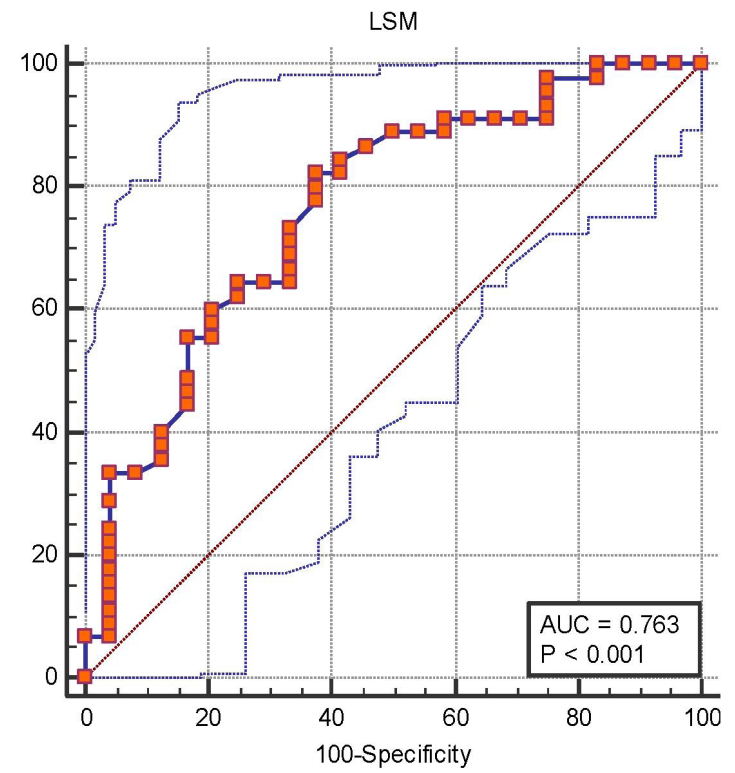

Gambar 1 Kurva ROC beserta nilai $p$ dan AUC 
hipertensi portal adalah 24 orang $(34,8 \%)$ sedangkan 45 orang mengalami hipertensi portal dengan distribusi 17 orang mengalami varises gastroesofagus, 7 orang mengalami gastropati hipertensi portal, dan 21 orang mengalami keduanya. Dari Fibroscan didapatkan LS terendah $11 \mathrm{kPa}$, tertinggi $75 \mathrm{kPA}$, dengan mean 29,89+17,75 kPa. Gambaran karakteristik data penelitian dapat dilihat pada tabel 1.

Berdasarkan data tersebut dilakukan analisis ROC untuk mengetahui AUC antara variabel LS dengan kelompok hipertensi portal yaitu akumulasi mereka dengan varises, GHP atau keduanya

\section{Tabel 1 Karakteristik data penelitian}

\begin{tabular}{lc}
\hline \multicolumn{1}{c}{ Variabel } & $\mathbf{n}(\%)$ \\
\hline Jenis kelamin & \\
- $\quad$ Laki-laki & $12(17,4 \%)$ \\
- Perempuan & \\
Etiologi & $22(31,9 \%)$ \\
- HBV & $7(10,1 \%)$ \\
- HCV & $6(8,7 \%)$ \\
- CLD & $34(49,3 \%)$ \\
- NA & \\
Manifestasi hipertensi portal & $17(24,6 \%)$ \\
- Varises gastroesofagus & $7(10,1 \%)$ \\
- GHP & $21(30,4 \%)$ \\
- Keduanya & $24(34,8 \%)$ \\
- Tidak ada & Terendah: $27 \mathrm{Tahun}$ \\
Umur & Tertinggi: $75 \mathrm{Tahun}$ \\
&
\end{tabular}

dengan total 45 orang dan kelompok tanpa hipertensi portal 24 orang. Dari analisis ROC diketahui Nilai $\mathrm{p}<0,0001$, dengan AUC 0,763. Kurva ROC dapat dilihat pada gambar 1 .

Analisis dilanjutkan dengan mencari nilai titik potong terbaik untuk nilai sensitivitas, spesifisitas, +LR dan -LR. Nilai titik potong terbaik yang didapat untuk memprediksi adanya manifestasi portal hipertensi LS adalah $>17,5 \mathrm{kPa}$, dengan sensitivitas 82,22\% (95\% CI 67,9-92,0\%), spesifisitas 62,50\% (95\% CI 40,6-81,2\%), +LR 2,19 (95\% CI 1,3-3,7), dan -LR 0,28 (95\% CI 0,1-0,6). Nilai titik potong dengan sensitivitas, spesifisitas, +LR, -LR dan 95\% CI masing-masing nilai dapat dilihat pada tabel 2. Berdasarkan hasil ini titik optimal untuk mencapai sensitivitas yang baik tanpa menurunkan spesifisitas secara bermakna adalah pada LS $>17,5 \mathrm{kPa}$ sehingga sesuai untuk alat skiring, sedangkan titik lainnya meskipun dapat digunakan namun menurunkan sensitivitas dan spesifitas secara bermakna sehingga tidak layak digunakan.

\section{DISKUSI}

Pada penelitian ini didapatkan bahwa nilai AUC TE adalah 0,763 dengan $\mathrm{p}<0,001$, dimana nilai LS $>17,5 \mathrm{kPa}$ memiliki hasil yang paling optimal dengan sensitivitas $82,22 \%$, spesifisitas $62,50 \%$, +LR 2,19 dan -LR 0,28. Berdasarkan hasil ini maka TE dapat digunakan sebagai alat skrining untuk kecurigaan hipertensi portal pada sirosis hepatis. Penelitian-penelitian sebelumnya juga menyimpulkan bahwa nilai LSM yang didapatkan dari TE (FibroScan ${ }^{\circ}$ ) dapat digunakan untuk mengurangi kebutuhan endoskopi pada pasien dengan sirosis hepatis. ${ }^{2,7}$

Perbedaan antara penelitian ini dengan konsensus Expanding Baveno VI terletak pada nilai LSM dan tujuannya. Pada konsensus expanding baveno VI, penderita sirosis hepatis dengan nilai

Tabel 2 Nilai cut-off beserta sensitivitas, spesifisitas, +LR, -LR dan $95 \% \mathrm{CI}$

\begin{tabular}{|c|c|c|c|c|c|c|c|c|}
\hline LS & Sensitivitas & $95 \% \mathrm{Cl}$ & Spesifisitas & $95 \% \mathrm{Cl}$ & +LR & $95 \% \mathrm{Cl}$ & -LR & $95 \% \mathrm{Cl}$ \\
\hline$\geq 11$ & 100 & $92,1-100$ & 0,00 & $0,0-14,2$ & 1,00 & $1,0-1,0$ & & \\
\hline$>15$ & 91,11 & $78,8-97,5$ & 37,50 & $18,8-59,4$ & 1,46 & $1,1-2,0$ & 0,24 & $0,08-0,7$ \\
\hline$>17,5$ & 82,22 & $67,9-92,0$ & 62,50 & $40,6-81,2$ & 2,19 & $1,3-3,7$ & 0,28 & $0,1-0,6$ \\
\hline$>22,5$ & 66,67 & $51,0-80,0$ & 66,67 & $44,7-84,4$ & 2,00 & $1,1-3,7$ & 0,50 & $0,3-0,8$ \\
\hline$>24$ & 64,44 & $48,8-78,1$ & 70,83 & $48,9-87,4$ & 2,21 & $1,1-4,3$ & 0,50 & $0,3-0,8$ \\
\hline$>27$ & 57,78 & $42,2-72,3$ & 79,17 & $57,8-92,9$ & 2,77 & $1,2-6,3$ & 0,53 & $0,4-0,8$ \\
\hline$>28$ & 55,56 & $40,0-70,4$ & 83,33 & $62,6-95,3$ & 3,33 & $1,3-8,5$ & 0,53 & $0,4-0,8$ \\
\hline$>40,9$ & 22,22 & $11,2-37,1$ & 95,83 & $78,9-99,9$ & 5,33 & $0,7-39,2$ & 0,81 & $0,7-1,0$ \\
\hline$>45,7$ & 20,00 & $9,6-34,6$ & 95,83 & $78,9-99,9$ & 4,80 & $0,6-35,7$ & 0,83 & $0,7-1,0$ \\
\hline$>75$ & 0,00 & $0,0-7,9$ & 100 & $85,8-100,0$ & & & 1,00 & $1,0-1,0$ \\
\hline
\end{tabular}


LSM $<20 \mathrm{kPa}$ memiliki risiko yang sangat rendah untuk mengalami varises yang membutuhkan penanganan sehingga endoskopi dapat di hindari. ${ }^{8}$ Sedangkan pada penelitian kami didapatkan bahwa nilai LS $>17,5 \mathrm{kPa}$ berisiko untuk mengalami manifestasi hipertensi portal seperti varises gastroesofagus dan atau gastropati hipertensi portal, sehingga sebaiknya dilakukan endoskopi untuk identifikasi dini.

\section{SIMPULAN}

TE dengan nilai $\mathrm{LS}>17,5 \mathrm{kPa}$ dapat digunakan sebagai alat skrining pada penderita sirosis hepatis untuk mengetahui adanya kecurigaan hipertensi portal yang bermanifestasi sebagai varises gastroesofagus dan atau gastropati hipertensi portal.

\section{KONFLIK KEPENTINGAN}

Penulis menyatakan tidak memiliki konflik kepentingan terkait publikasi dari penelitian ini.

\section{PENDANAAN}

Penelitian ini tidak mendapatkan pendanaan oleh pemerintah ataupun lembaga swasta lainnya.

\section{KONTRIBUSI PENULIS}

I Made Wisnu Wardhana, Gde Somayana, I Ketut Mariadi, I Dewa Nyoman Wibawa berkontribusi terhadap desain dan implementasi penelitian, analisa data hingga penulisan manuskrip.

\section{DAFTAR PUSTAKA}

1. Merli M, Nicolini G, Angeloni S, et al. Incidence and natural history of small esophageal varices in cirrhotic patients. Journal of Hepatology 2003; 38: 266-272.

2. Schepis F, Camm 'a C, Niceforo D, et al. Which patients with cirrhosis should undergo endoscopic screening for esophageal varices detection?. Hepatology 2001; 33: 333-338.

3. Sanyal AJ, Bosch J, Blei A, Arroyo V. Portal hypertension and its complications. Gastroenterology 2008; 134: $1715-1728$.

4. Maruyama H, Yokosuka O. Pathophysiology of portal hypertension and esophageal varices. International Journal of Hepatology 2012; 1-7.

5. Bloom S, Kemp W, Lubel J. Portal hypertension current concepts. Intern Med J 2015; 45: 16-26.

6. Procope B, Tantau M, Bureau C. Are There any Alternative Methods to Hepatic Venous Pressure? Gradient in Portal Hypertension Assessment?. Journal of Gastrointestinal Liver Disease 2013; 22(1): 773-85.

7. Kazemi F, et al. Liver stiffness measurement selects patients with cirrhosis at risk of bearing large oesophageal varices. Journal of Hepatology 2006; 45: 230 - 235.

8. de Franchis $\mathrm{R}$ on behalf of the Baveno VI Faculty. Expanding consensus in portal hypertension Report of the Baveno VI Consensus Workshop: Stratifying risk and individualizing care for portal hypertension. Journal of Hepatology 2015; 63: 743-752.

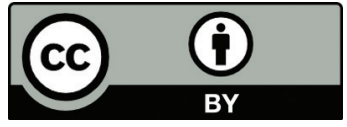

This work is licensed under a Creative Commons Attribution 